\title{
Honesty honestly, an alternative approach to academic honesty
}

\author{
John Royce \\ Ebley, Stroud, \\ England \\ jroyce@read2live.com
}

\begin{abstract}
Research studies and experience suggest that many students just do not understand citation and referencing. They say they know the rules, they seem to know the rules, yet still they make mistakes, sometimes with heavy consequences.

For those who do understand, there is no problem. For those who understand what is expected by way of good practice, the main difficulty may be understanding the understandings of those who do not understand, those who do not mean to cheat but who still break "the rules."

In this paper, I investigate sources of confusion, and possible disconnects between those who teach citation and referencing and those who learn and use these techniques. The study includes a series of surveys of librarians, teachers and students. Strategies and techniques to promote better understanding and better practice are suggested. Teacher-librarians are well-placed to promote and ensure good practice.
\end{abstract}

Keywords: Academic writing, Academic honesty, Citation, Referencing, Plagiarism

\section{Definitions and understandings}

In the world of academia, plagiarism is decried, whether deliberate or unintentional. Consequences may be different, but not always. Certainly, there are degrees of plagiarism. At one extreme we would include submission of papers written completely by someone else, deliberate cheating. Usually cheats know what they are doing and they know that what they are doing is wrong.

At the other extreme there might be occasional omission of quotation marks, or the putting of the wrong name to the wrong quotation, or failure to distinguish between a paraphrase and a direct quotation. While such academic infringements may be made knowingly and with intent to cheat, they might also be due to carelessness, or to ignorance or failure to learn the right way to use other people's work, or poor study habits and notemaking techniques. The reasons why students make mistakes are many.

Much of the focus of this paper is the second type of infringement, the unknowing, unintentional error in citation or referencing. I believe there is much confusion with regard to citation and referencing and with regard to plagiarism. The definitions are confused and confusing, misleading and sometimes just plain wrong; teachers, students, examiners and the writers of curriculum may be similarly confused. 
The intention is to explore the extent of confusion, and to consider any disconnect between those who teach citation and referencing and those who learn and use these techniques: is what is being taught (and learned) the same as what is needed? Where do the confusions occur, how do they arise?

Immediate sources of confusion are the terms "citation" and "reference" and verbs derived from them. Some style guides use the terms interchangeably. Some use them in ways directly opposite to the usage in other guides. The Publication manual of the American Psychological Association (APA) uses the term "citation" to denote a short form of attribution in the text which links to a full "reference", usually at the end of a paper in a list of References (2009, p. 174). This is the usage in this paper. (Other guides may call this a "Bibliography," or a list of "Works Cited".)

In-text citations may be used in the sentence, introducing a quotation, paraphrase, statistic or similar, or at the end (in parentheses), or indicated by a (superscript) number which links to a footnote. They may be split, with the author's name in a signal phrase at the start of the paragraph and the date and/or page number parenthetically at the end.

Another source of confusion is "plagiarism." This term is difficult to define. Many definitions and descriptions are incomplete and unhelpful.

The Joint Council for Qualifications, for instance, defines plagiarism as "unacknowledged copying from published sources or incomplete referencing" (JCQ, 2014, p.39), suggesting that incomplete references make for plagiarism, while perhaps also suggesting that copying from unpublished sources is acceptable; moreover, this definition fails to mention a need for quotation marks or similar device when copying.

OCR, an international examinations board, has a long definition and guidance for exams in Humanities - but again fails to mention the necessity of quotation marks or indentation (2012, p.3).

Guidance given in the University of Southampton's General Regulations (n.d.) is also flawed, suggesting that references must be "correctly formatted" in order to avoid a charge of plagiarism. Incorrect references might indicate plagiarism, but incorrectly "formatted" references do not, the writer is still being honest.

These are but a few examples of misleading or incomplete definitions of plagiarism. Indeed, it may be easier to describe good practice, including:

- clear distinction between the writer's own words, work or ideas and those of others;

- indication of who those others are, at the point of use;

- use of quotation marks or other device to signal when someone else's exact words have been used. 
Failure to include any of these elements could give a reader or viewer the impression that "this" is yours when "this" is the words, work or ideas of someone else - and we still need regard for the possibilities of self-plagiarism and allowances made for common knowledge.

These three elements make for honesty. Academic honesty goes further, giving enough detail that the interested reader can track or trace the exact work used, thus the emphasis on bibliographic references in addition to citation. Nevertheless, if the writer makes clear in the text what material is the writer's own and what comes from other sources, any mistakes are lapses of scholarship, not academic dishonesty.

It is not just the notion of plagiarism that is difficult to define. It is tempting to think that we know what plagiarism is when we see it.

Jude Carroll's "Where do you draw the line?" (2007, p. 52) and variations thereof suggest otherwise; use of this instrument in classrooms and in workshops shows wide disagreement as to what is academically acceptable and required: teachers and students consistently draw the line in different places.

Studies based on Carroll's exercise at the University of Leeds in 2006 (no longer available) showed that $37 \%$ of students drew the line too low: they were in danger of plagiarizing, thinking their practice was acceptable. Of even greater concern was that $32 \%$ of teaching staff also drew the line too low: they would accept writing which breached standard acceptance of acceptable use, and so reinforce student misperceptions.

Students might honestly claim, "But I've always done it this way ..." but it does not help if "this way" is the wrong way. A study of first-year students at a university in New Zealand found that only 12 of 91 first-year students who claimed that their understanding of plagiarism was "good" or "very good" appeared also to know that that they needed to indent or put quotation marks around quoted text (Emerson, MacKay \& Rees, 2005, pp.90-91).

A more recent study by Newton finds the same true of British undergraduate students: many have "misplaced confidence in their ability to recognize [and to avoid] plagiarism" (2015, p.14).

\section{"First in, last out"?}

Chanock points to the problem of students who think they know what they should do in their writing, and may well switch off when they hear yet another talk on academic honesty; she suggests that

[Students] fail to reference 'properly' not because they do not know about attribution, but because they do know about it and think they are doing it right ... It is probably their confidence that they know the rules that allows them to ignore the copious guidelines set out in their subject guides (2008, p.5).

Shahabudin echoes this, pointing to the problems of "students believing, for instance, that they 'know' how to use references at university because they have used them at school" (2009, pp.2-3). 
Examples of confusion abound.

A few years ago, American politician Rand Paul was accused of lifting his summary of the plot of the movie Gattaca from Wikipedia, word-for-word. Paul claimed that he had not plagiarized, on the grounds that he had named the movie in his speech (Lavender 2013). He seemed oblivious to the notion that the words he used were not from the movie but from a source describing the movie.

College presidents and school principals seem particularly prone to using other people's words without attribution, especially in graduation speeches. There are so many cases each year that one might think they would get to be aware, but apparently not. Their excuses are often reminiscent of a 9th grade student (see, for instance, press reports by Garcia, 2014; Grider, 2014; Harris, 2014; Sakoda, 2014).

Elsewhere, plagiarism expert Jonathan Bailey has recounted how, when still a student, a professor confronted one of his classes. He stormed into the room and declared that somebody in the room had plagiarized on the latest assignment. He wanted the culprit to own up. Bailey continues:

The students, all 30 of us, wondered who it was but were more worried that it was us. Many of us began to talk openly about that fear saying things like "I didn't plagiarize but... I hope it wasn't me" (2010, Section: The climate of fear).

Many know - or appear to know - but perhaps they do not.

Meanwhile, Colin Neville's studies suggest that many students, perhaps scared by fear of accusations of plagiarism, lose their "voice" and use "defensive forms of writing" (2012, p.2); they make excessive use of quotations, using other people's work to say what they want to say, as against saying what they want to say and then using other people's work to support their position (2010, slide 12; 2012). This is the opposite of Newton's students with their "misplaced confidence," but just as problematic.

For those who do understand, there is no problem. For those who understand what is expected by way of good practice, the main difficulty may be understanding the understandings of those who do not understand, those who do not mean to cheat but who still break "the rules."

\section{The surveys}

Aiming to explore possible sources of confusion, I conducted several "surveys" over several months. There is nothing scientific about these surveys in that respondents, mostly at specific workshop events, were asked to participate, an "opportunistic sample". As such, they are unlikely to be representative of general teaching or school populations. None of the groups was large. The questions were open-ended, inviting textual responses; many respondents gave multiple responses to various of the questions, making quantitative analysis difficult.

Nevertheless, these surveys may be indicative, and do suggest that follow-up would be worthwhile. 
The surveys were presented to four distinct groups, school librarians, teachers, administrators and students. A large number of librarians answered during a librarians' conference in Waterloo in 2014. Several more groups responded to the same questions during IB librarians' workshops in the next few months. Teachers and administrators in other workshops taking place at these same venues were also invited to respond.

In addition, teachers and students at two schools also took part, one in the Middle East, the other in Scotland.

Responses to the workshop surveys were on paper; the schools' surveys were administered through SurveyMonkey.

Administrators were asked:

- What (if anything) do you think students find difficult about citation and referencing?

- What (if anything) do you think teachers find difficult about teaching citation and referencing?

Administrators were almost unanimous in declaring that teachers have too many styles to choose from, and that teachers are inconsistent in their expectations and requirements.

Administrators believed students too are confounded with too many styles, and have difficulty appreciating that anything that is not their own needs citing in the text.

Teachers were asked:

- What (if anything) do you think students find difficult about citation and referencing?

- What (if anything) do you find difficult about teaching citation and referencing?

Teachers think there are too many styles from which to choose; many think the teaching of referencing is tedious, especially teaching "correct" formatting.

Many teachers think that students find referencing difficult because it is new to them, and there are too many styles from which to choose; the complexities of formatting were often mentioned as well, in particular inconsistencies and exceptions. A few teachers suggested that students most often have problems with in-text citation, not knowing when or how to cite sources in the text.

More than one-third of teachers at the Middle Eastern school responded along the lines of "Too many different style guides - please choose just one style." What is particularly problematic about this response is that the school uses and expects MLA only - there is just the one style guide in use in the school.

Several teachers at the school in Scotland made similar comments, loudly. This school promotes the use of Harvard for its IB classes for the Diploma Program, but the situation is complicated in that IB is just one of three different examinations boards for which this 
school's students may sit, and the guidance given by at least one board is - as discussed in the next section - unhelpful and contradictory.

Librarians were asked:

- What (if anything) do you think teachers find difficult about teaching citation and referencing?

- What (if anything) do you think students find difficult about citation and referencing?

- What (if anything) do you find difficult about teaching citation and referencing?

The most common comments by librarians, with regard to teachers, were that

- many make no attempt to include assessment of citation and referencing in their assignments, even those involving research in the library or online;

- many have no notion of what to expect by way of citation and referencing;

- many have fixed ideas about what constitutes "correct" referencing, often based on out-dated editions of style guides;

- there is not enough teaching of how to write, how to incorporate other people's work into students' own work;

- there is often a failure to point to or to role-model good practice.

With regard to librarians' perceptions of students' difficulties, there was repeated mention of

- difficulty identifying the type of source to be referenced;

- difficulties getting the formatting, especially the punctuation, right;

- many understanding referencing but having difficulty using in-text citation;

- poor work habits such as failure to note the source at a time when notes or copy-paste quotations were made.

Of their own difficulties as librarian, a great many reported difficulty in

- getting teachers to work with them;

- being expected to teach citation and referencing out-of-context and with no opportunity for students to practice;

- making citation and referencing interesting, relevant or fun;

- persuading teachers that they needed at least to comment on and possibly to assess students' use of sources;

- getting students to understand how their choice of sources can add value and authority to the work.

Students were asked:

- What (if anything) do you find difficult about teaching citation and referencing?

More than half of those who responded claimed to have NO problems with citation and referencing in general. That said, more than half also claimed to have difficulty with the requirements of correct formatting. About one-tenth of the student respondents recognized that they might do better if they were more organized in their notemaking, most especially making note of sources at the time they made the note or copy-pasted, rather than seeking sources afterwards, once the work was written. 
Clearly there is scope for further and more controlled research; a more thorough questionnaire might include questions on the style guide/s used at the school, the style/s used by the respondent, the training and guidance given to students and to teachers, understanding of the purposes of citation and referencing, and more. It would be useful to know the curriculums and the examination systems followed. Suggested responses could be posed to many of the questions, which could reduce any uncertainty as to the meaning, especially with regard to the meanings of "citation" and "reference."

The findings of these surveys with regard to students are borne out by a similar but unpublished survey/audit conducted by another school, this in northern Europe. This survey included questions which presented possible ways to use quotation, citation and references, some of which were right and some wrong (according to the style guide used by the school, MLA). In this artificial situation, artificial because it was a test, the suggested responses having no context, most students selected the right answers.

So much depends on what students are taught - and when they are taught it, how much practice they get and how much feedback they get. If they are not taught, they may never learn. If they are taught the wrong things, they may have difficulty losing what they first learned and learning the right approach. If they are not taught why referencing and citing are important, and how each element of the reference adds value to their writing, it will be seen as boring, tedious and pointless.

\section{Conflict and confusion}

The professional reference generator Endnote suggests that there are "more than 6,000 bibliographic styles" (Endnote Output Styles, 2014). While many may be duplicate and certainly very similar, some are different indeed. Here is one possible source of and for confusion.

If an examinations board does not name or require a specific style, it is not possible for an examiner to decide on whether a reference is accurately formatted.

The International Baccalaureate, for instance, does not prescribe a named style, be it for all assessments or for use in any given subject. IB argues that with teachers, students and examiners having so many different educational backgrounds, training and languages, it is not fair to prescribe particular styles. For the IB, consistency and completeness of references is regarded as more important than notions of accuracy.

Not all examinations boards are as flexible, the Scottish Qualifications Authority, for instance, one of the boards used by the school in Scotland taking part in the survey.

Not all SQA subjects give guidance on referencing, but of those which do, most give examples using an author-date style. SQA Geography (n.d.) recommends Harvard by name.

Harvard is a problem style. Unlike APA with its Publications Manual, MLA with its Handbook for Writers of Research Papers, or Turabian/Chicago with A Manual for Writers of Research Papers, there is no one published and authoritative guide to Harvard. Universities, schools, publishers and examinations boards compile and publish their own Harvard guides, and there may be differences between any two versions. 
As is the case with SQA subjects. Different subjects use different versions of Harvard. The differences are telling. Different punctuation, capitalization, style and use of parentheses, use of full-stops. Different formatting of dates, different requirements for the elements to be used in a reference, different order of elements.

Some subjects show inconsistencies within their own guidance, never mind differences to other subjects.

It is not surprising that a large number of survey responses from this school, from students and from teachers, expressed confusion and frustration.

One subject, Chemistry, gives very precise instruction:

References ... must be correctly cited in the text and listed correctly at the end. In your Chemical Investigation the only acceptable method of citing and listing references is shown below ...

(emphasis as in the original, SQA AH Chemistry, 2015, p.9).

Precise - yet the examples given, for references and for in-text citation, break with most academic convention. The page numbers for quotations are included in the references at the end, not at the point-of use in the report. Web pages need only the URL and the date visited; author and titles are not used, are "not acceptable" (p.10). Only one form of in-text citation is permitted, and these examples are questionable; they could be examples of plagiarism (Royce, 2015).

As discussed in the next section, some (but not necessarily all) secondary school students may learn and be able to use several different referencing systems, a footnoting system, an author system, an author-date system.

Students taking two or three different SQA subjects, however, may have to learn two or three different variations of the same style, and with no manual, no handbook, no website or online reference generator to guide them. This is not so easy; no wonder so many survey responses showed frustration and confusion. Teachers teaching the same subject but for different examination boards are also confused and confounded. Comments made in email correspondence by this school's librarian suggest that it is not just fear of plagiarism which grips these students and their teachers.

The Scottish Qualifications Authority is easy to investigate, because so many subjects openly publish their guidelines. It could be worth those with access investigating closely the guidelines published by other examinations boards.

\section{How many styles?}

Should schools adopt one style, or teach and give opportunities to practice several or many styles? There may be no one-size-fits-all response to that question, there are so many factors involved. One factor will be the demands, expectations and requirements of examination boards. Another might be the demographic of the students and teachers, 
whether there is much or little turnover of students or teachers each year, and what newcomers have already learned.

Age and maturity of students are also factors. I believe that once students have understood one referencing system and in particular WHY we cite and reference, and HOW each element of a reference contributes to the writing and to the finding of the sources used, they will be more ready to learn other systems. Students who are taught simply to follow a template or pattern but without those understandings are more likely to be confused when asked to use a different style. (The problems when an examinations board provides inconsistent and "inaccurate" examples and demands are different issues.)

When conducting an in-school conversation as to which or how many styles to promote, it is worth remembering that teachers find it difficult when they encounter different styles. Many are used to just one style, often the style (probably out-of-date) they learned at college or university. If teachers find it difficult to use more than one referencing style, should we expect students to learn and to use many?

In a thread in the ECIS librarians' online forum, Katie Day provides a useful model. In her school, all students are taught and use MLA up to grade 10. Once they start their IB diploma courses, they may be introduced to styles sometimes considered more appropriate for particular subjects (2015).

The earlier we start, the better. The more practice students get, the better - and practice means attention paid to the use of citation and references, and not just in terms of "correctness." Some syllabus options and some examinations boards, unfortunately, do not require much by way of individual research and inquiry, as suggested by A.T.: "As IGCSE is very textbook based and there isn't a need for research, there is no teaching of such skills in these years" (personal communication, March 4, 2015).

\section{In-text citation - when?}

One issue might be that many schools teach and require the use of bibliographical referencing well before introducing in-text citation.

Dianne McKenzie, a colleague I much respect and admire, has blogged about her path to creating a scope-and-sequence schema for referencing in grades 7 to 12 . Starting with an audit of what teachers at each year level require, and drawing on the skills which students need by year 11, the start of the IB Diploma Programme, she and the Middle Years Programme coordinator together devised the scope-and-sequence plan.

The schema places emphasis on correct formatting of bibliographical references throughout the middle school years. Attempts to cite quotations in-text are expected by year 8 , but in-text citation of paraphrases is not introduced until year 10. Asked why in-text citation of paraphrasing is not required earlier, McKenzie responded that it is not needed earlier, and in any case students are faced with so many other new requirements that it is left until late in the course (McKenzie, 2014). 
Should it be needed earlier, could it be needed earlier? So much depends on the teachers, so much depends on the curriculum and the opportunities given to practice using other people's work.

Academic honesty guru Jude Carroll believes that IB Primary Years Programme (PYP) children can learn how to use quotation marks and forms of acknowledgement in the text (Carroll, 2012, p 4). It does not have to be accurate per published style guide; it may be enough for a 7-year old to write "Mummy says that ..." or "I read in the red book how ..."

To extend the point, in an IB OCC forum, Philip Williams asked for comments on a citation mapping sequence which included "In-text citations : introduced to Grade 10" (Williams, 2014). I replied, pointing to Carroll's thoughts and suggesting an earlier start. A year later, Williams posted again:

I have taken your advice and been discussing how in-text citation is a part of the PYP classroom. This has caused a few double-takes soon followed by nods of understanding as people see the deeper purpose of in-text citation (2015).

The earlier, the better. It is possible, and it is helpful.

Not helpful is the role-modelling presented by a practice activity for GCSE History on the BBC's online education site. The reader is given a quotation as source material, and asked to use information and ideas from the quotation, along with the reader's thoughts and prior knowledge, to devise a new paragraph. The suggested model answer might satisfy an examiner, but there is no in-text citation, there is nothing to indicate what information comes from the source quotation and what is the writer's own (BBC GCSE Bitesize, 2014).

Opportunity missed.

\section{Writing as process - why we cite}

Understanding WHY we cite seems fundamental. Without this understanding, students are just jumping through hoops.

In classes and workshops, when I ask students or teachers WHY we cite and reference, how these devices are helpful to the writer and how they are helpful to the reader, the answers given are usually on the lines of:

- to be honest, to avoid plagiarism;

- to show clearly what IS NOT ours - and to say that everything else IS ours (words, ideas, pictures, etc.);

- to say thank you, to show respect, to give credit where it's due;

- to show we have researched widely;

- to strengthen our arguments;

- to show we know (perhaps to discount) the counter-arguments;

- to add credibility through our choice of support;

- to build on what is known;

- to allow the interested reader to follow up;

- to share the blame if we get it wrong!

- it's what scholarship is all about, it is what scholars do. 
Curiously, of all the reasons we give for citing and referencing, only the first and perhaps the second have anything to do with academic honesty. Even the first reason is mixed. Ideally, we cite our sources, not to "avoid plagiarism," but because we are honest, we have integrity. We say what is not ours because it is the right thing to do. It is what we do, who we are. All the other reasons for citing sources are connected with writing, with good argumentation, with providing strong evidence and support for our line of thought, with helping the reader, with demonstrating our worthiness to join the academic discussion.

Learning and understanding why we cite, and how each element of a reference adds to the authority and credibility and re-traceability of our writing are lessons which will stick - and will make transfer from one referencing system to another far easier.

Then we can discuss readability, and signal phrases and the verbs we use, we can discuss authority.

We can use other people's work to demonstrate good practice, and discuss practice which is less helpful, as well. Newspaper reports of scientific papers often provide fertile material for discussion, and sometimes the papers themselves.

Research should be fun; references - and referencing - should have point. Students are good at finding evidence to support their own viewpoints. Follow-up work might require them to find evidence which refutes their arguments and to present an opposite point-of-view.

Dianne McKenzie, mentioned earlier in connection with her referencing audit, has also described how she co-planned and co-taught a unit on MYP Humanities - and how much it taught her about how students write, how they use other people's material, where the weaknesses were and what aspects of the writing process needed more attention (MacKenzie, 2013).

Getting involved in the process can be so very useful. It is informative and empowering. It helps enforce and reinforce good practice.

One of the issues that might emerge from close co-teaching - or from a survey - is awareness of how students work. One common response of students in the schools surveyed suggests poor notemaking habits. Many students said that they complete their essays, and then have to go back to find their quotations and paraphrases, then try to find the originals so they can cite and reference them. This is inefficient, and dangerous if a citation is missed.

Part of an efficient writing process should be the recording of useful quotations and ideas as one comes across them. It can be useful to teach students appropriate use of notecards or other form of notemaking, be it on paper or electronically. Students should be encouraged to note at least enough bibliographic detail to enable retrieval of a source should the material be used in the essay, on a master list rather than on each individual notecard. Details do not have to be correctly formatted per style guide, not at this stage, but they should be as complete as is necessary. It saves so much later. 


\section{Honesty honestly, in conclusion}

There is a disconnect, but not the one I had in mind when embarking on this investigation. Students can and do reference. They, and their teachers, may be confused in the formatting of references to a particular style, often not helped by conflicting instruction and example, but this is not the disconnect.

Any disconnect lies in misplaced emphasis on academic honesty as against honesty, pure and simple. Honesty in writing lies in the citation, the indication in the text at the point of use that "this" is not mine. Inculcating and expecting honesty enables us to concentrate on the message, on what is written. We can start early, expecting honesty by (age-appropriate) means of citation, and expecting it all along. Honesty should not be a chore.

Referencing is not about academic honesty. It is about writing, the sources we use to add weight to our writing, add authority and credibility. Referencing can be introduced when children are ready. Consistency of format can be a chore, if introduced too soon or too rigidly and seemingly without point. Our task is to add point, demonstrating the added value of good sources and good referencing.

School librarians, often at the forefront of teaching citation and referencing, often charged with discovering plagiarized sources, often with an overview of curriculum which subject teachers usually lack, are well-placed to guide, teachers as well as students.

\section{References}

Bailey, J. (2010, May 10). How schools are hurting the fight against plagiarism. Plagiarism Today. [Web log post]. Retrieved from http://www.plagiarismtoday.com/2010/05/10/how-schools-are-hurting-the-fightagainst-plagiarism

BBC GCSE Bitesize. (2014). History : Exam skills : Sources in context. Retrieved from http://www.bbc.co.uk/schools/gcsebitesize/history/examskills/sourcesincontextrev1 $\underline{\text { shtml }}$

Carroll, J. (2007). A Handbook for Deterring Plagiarism in Higher Education. Oxford, UK: Oxford Centre for Staff and Learning Development.

Carroll, J. (2012). Academic honesty in the IB : IB position paper. Cardiff, UK: International Baccalaureate.

Chanock, K. (2008). When students reference plagiarized material - what can we learn (and what can we do) about their understanding of attribution? International Journal of Academic Integrity, 4 (1), 3-16. Retrieved from http://www.ojs.unisa.edu.au/index.php/lJEl/article/view/191/142

Day, K. (2015, March 6) Re: Referencing and researching tools [Electronic mailing list message]. Retrieved from http://www.iskoodle.com/mod/forum/discuss.php?d=5307\#p17744 
Emerson, L., MacKay, B., \& Rees, M. (2005). Plagiarism in the science classroom: Misunderstandings and models. Proceedings of the 2nd Asia Pacific Educational Integrity Conference Newcastle, Australia (pp 88-98). Retrieved from http://www.newcastle.edu.au/conference/apeic/booklet/APEIC05proceeding.pdf

Endnote Output Styles. (2014). Retrieved from http://endnote.com/downloads/styles

Garcia, N. (2014, June 10). Principal explains why he plagiarized graduation speech. 9 News. Retrieved from http://www.9news.com/story/news/education/2014/06/10/principal-plagiarismgraduation-speech/10306299/

Grider, K. (2014, June 18). Letters to the editor. Brookville American Democrat. Retrieved from http://www.whitewaterpub.com/AAAissues/brookville/2014/25/letters01.php

Harris, B. (2013, Sept 4). Superintendent accused of plagiarizing welcome letter. Fox8. Retrieved from http://fox8.com/2013/09/04/superintendent-accused-of-plagiarizingwelcome-letter/

JCQ. (2014). General and vocational qualifications: Suspected malpractice in examinations and assessments: Policies and procedures, 1 September 2014 to 31 August 2015. Retrieved from http://www.rewardinglearning.org.uk/microsites other ladmin handbook/docs/malpractise 14 15.pdf

Lavender, P. (2013, October 30). Rand Paul addresses plagiarism claims: "I gave credit." Huffington Post. Retrieved from http://www.huffingtonpost.com/2013/10/30/rand-paul-plagiarism n 4179395.html

McKenzie, D. (2013, March 2). Assessing for learning. Library Grits [Web log post]. Retrieved from http://librarygrits.blogspot.co.uk/2013/03/assessing-forlearning.html

McKenzie, D. (2014, May 14). ATL skills audit. Library Grits [Web log post]. Retrieved from http://librarygrits.blogspot.co.uk/2014/05/skills-audit.html

Neville, C. (2010). Student perceptions of referencing. Open University. Retrieved from http://www.open.ac.uk/about/wideningparticipation/files/wideningparticipation/Brief \%20overview\%20of\%20research.ppt

Neville, C. (2012, April-June). Referencing: Principles, practice and problems. RGUHS Journal of Pharmaceutical Sciences 2(2). doi:10.5530/rjps.2012.2.1

Newton, P. (2015). Academic integrity: A quantitative study of confidence and understanding in students at the start of their higher education, Assessment \& Evaluation in Higher Education, doi:10.1080/02602938.2015.1024199 
OCR (2012). A2 GCE Humanities, Unit G104: Interdisciplinary Skills Research Enquiry: Guidance for candidates. Retrieved from http://www.ocr.org.uk/Images/81871-unitg104-interdisciplinary-research-skills-enquiry-specimen.pdf

Royce, J. (2015, April 10). Harvard on my mind - 2. Honesty, honestly [Web log post]. Retrieved from http://www.read2live.com/2015/04/09/harvard-on-my-mind-2

Sakoda, C. (2014, June 18). High school principal congratulates wrong school in plagiarized graduation message. Yahoo News. Retrieved from http://news.yahoo.com/blogs/odd-news/high-school-principal-congratulates-wrongschool-in-plagiarized-graduation-message-210035090.html

Shahabudin, K. (2009, February). Reaping the fruits of collaboration - learning development research in the LearnHigher CETL network. Journal of Learning Development in Higher Education (1). Retrieved from http://www.aldinhe.ac.uk/ojs/index.php?journal=ildhe\&page=article\&op=view\&path[ l=35\&path[]=23

SQA. Geography . (n.d.). Examples of Referencing: Geography : Improving Candidate Performance. Retrieved from http://www.sqa.org.uk/sqa/8479.html

SQA. AH Chemistry. (2015). Advanced Higher Chemistry Investigation Guidance. Retrieved from http://www.sqa.org.uk/sqa/files ccc/AH Chemistry InvestigationGuidance 2015.pdf

University of Leeds. (2006). Staff perspectives of plagiarism. Retrieved from http://www.Idu.leeds.ac.uk/polls/poll_result.php?POLL=8 (no longer available).

University of Leeds. (2006). Student perspectives of plagiarism. Retrieved from http://www.ldu.leeds.ac.uk/polls/poll_result.php?POLL=9 (no longer available).

University of Southampton (n.d.). General Regulations, 10b. Retrieved from http://www.studyskills.soton.ac.uk/integrity/referencing/references 04.htm

Williams, P. (2014, February 11). Academic honesty: citing sources, OCC Academic honesty forum. [Electronic mailing list message]. Retrieved from http://occ.ibo.org/ibis/occ/fusetalk2/forum/messageview.cfm?catid=84\&threadid=38 $\underline{42227 \& \text { enterthread }=y}$

Williams, P. (2015, February 8). Academic honesty: citing sources, OCC Academic honesty forum. [Electronic mailing list message]. Retrieved from http://occ.ibo.org/ibis/occ/fusetalk2/forum/messageview.cfm?catid=84\&threadid=38 $\underline{42227 \& \text { enterthread }=\mathrm{y}}$

\section{Biographical note}

John Royce has worked as teacher and librarian in schools in Zambia, England, Malawi, Germany and most recently at Robert College of Istanbul in Turkey. He has served two terms as IASL Regional Director for North Africa and the Middle East and three terms as 
Chairman of the ECIS Librarians' Committee. He won the IASL International School Librarianship Award in 2011-12. He is the author of Credit Where It's Due: The School Library Preventing Plagiarism (pub. UK School Library Association) and blogs on academic honesty at http://read2live.com/. Required to "retire" in 2012 on grounds of age, he now works as a freelance consultant, presenter, workshop leader and writer. 